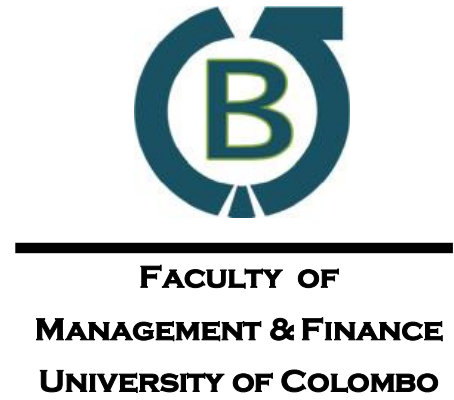

UNIVERSITY OF COLOMBO
Vol. 04, No. 01, June 2013
Colombo

Business

Journal

International Journal

of Theory \& Practice

\title{
The Impact of Environmental Regulation on Technological Innovation and Competitive Advantage: A Case Study of Sulphur-free Gasoline
}

\author{
T. Miki ${ }^{\text {a }}$ \\ College of Business, Rikkyo University, Japan
}

\begin{abstract}
In this paper, I present the impact of environmental regulation on technological innovation and competitive advantage. Previous research has verified that several aspects of environmental regulation, such as economic incentive, anticipation, stringency and certainty drive new technologies. However, such research merely pays attention to the technological innovation within each firm. How does some technological innovation diffuse within the industry and how does the firm get competitive advantage confronted with the environmental regulation? To answer this question, I use the case study strategy. The case describes the process of developing sulphur-free gasoline that reduces the $\mathrm{CO}_{2}$ emission volume developed by a major Japanese oil company. Through the case analysis, I show that technological innovation before regulation have a possibility to provide the firm high quality finished technological innovation and also provide the firm a chance of creating competitive advantage.
\end{abstract}

Keywords: Environmental regulation, Technological innovation, Competitive advantage, Sulphur-free Gasoline

\section{Introduction}

Many scientists have known about greenhouse effect for over a century. The greenhouse effect is caused by radiation of sun that is reflected off the earth's surface and trapped by $\mathrm{CO}_{2}$ and other greenhouse gases (GHG) in the atmosphere. This natural greenhouse effect increases the global mean temperature warm enough to sustain life on Earth. On the other hand, burning fossil fuels cause increasing $\mathrm{CO}_{2}$ emissions. It is said that humans have altered this basic mechanism into additional human induced greenhouse effect known as "global warming".

The Kyoto Protocol, which was held in December 1997 in Japan, was one of the epochs making event for such global warming issues. It attempted to bring the nations together in reducing

${ }^{a}$ Corresponding author: miki@rikkyo.ac.jp 
greenhouse gases. In accordance with the Kyoto Protocol, Contracting Parties from developed countries are committed to reducing their combined greenhouse gas emissions by at least 5 per cent from 1990 levels by the period 2008-2012. According to the International conferences such as Kyoto protocol for global climate issue, some will spend time on technological innovation. Others will establish regulations to protect global climate.

In this paper, I focus on the relationship between environmental regulation and creating competitive advantage by technological innovation. From the standpoint which the environmental regulation induces the technological innovation, I postulate how the company can get competitive advantages through developing and diffusing technological innovation.

The research issues are not new. Many environmental regulations existed before Kyoto-protocol. However, the more environmental regulations has been (or will be) issued recently (or in the future), the more focus on environmental protection have been paid all over the world such as Kyoto-protocol. This phenomenon makes this research issue more important.

\section{Review of Previous Research}

\subsection{Acceptance of Technology Innovation}

At first, I discuss how and why new technology innovation is accepted. Much of previous research has addressed these questions.

One of the typical viewpoints is technological determinism. This viewpoint insists superior technology will replace inferior technology. Accordingly, what firms have to do is to concentrate solely on the development and acceptance of superior technologies. Moreover, the government just has to back up for superior technologies (Liebowitz \& Margolis, 1990). However, the reality is different. The reason is the difficulty in resource mobilization.

To realize the innovation which produces economic results asks for two pre-requisites (Takeishi, Aoshima, \& Karube, 2008). One is "knowledge creation," by which the ground breaking ideas on technologies, products and businesses are created (Lundvall, 1992; Nonaka \& Nagata, 1995). Another is "resource mobilization," by which resources are mobilized for the process of linking ground breaking ideas that have been created to gain economic results. The former item, "knowledge creation," involves the management of individuals. But if the ideas generated by that effort are to be linked to innovation as an economic result, "resource mobilization" is essential. Innovation harbours a paradox in that "resource mobilization" is indispensable to innovation, yet "resource mobilization" is difficult precisely because it is for innovation (Takeishi et al., 2008). No matter how innovative an idea, without persuading others and without cooperation in terms of resources, that idea won't be realized. The reason is because innovation is influenced not only by technological and economic considerations but also by social and political factors (Tushman \& Rosenkopf, 1992).

Thus previous research focused on characteristics of technology as one factor affecting innovation acceptance and the market rivalry among firms (e.g. Abernathy \& Clark, 1985; Dewar \& Dutton, 1986; Ettlie, Bridges\& O'Keefe, 1984; Forster, 1986; Henderson \& Clark, 1990; Leonard-Barton, 1992; Nelson \& Winter, 1982; Teece, 1986; Tushman \& Anderson, 1986). In particular, the point first taken up in debates was the difference in the key performance of new technologies and existing technologies. The change in key performance resulting from a shift to new technology clarifies the 
superiority or inferiority of the new technology's performance vis-à-vis existing technologies, providing an indicator when a firm decides the orientation of its technology transition.

However, the innovation orientation will not be determined solely by the technological characteristics of existing and new technologies. If a firm lacks the physical resources, or management resources in the form of technical knowledge, for evaluating the characteristics of a technology, an innovation will not be accepted and not be linked to commercialization.

Previous research that has compared the technological characteristics of existing and new technologies also argue that the possibility of applying a firm's existing resources will determine the acceptance of innovation (Abernathy \& Clark, 1985; Christensen, 1997; Forster, 1986; Henderson \& Clark, 1990; Leonard-Barton, 1992; Tushman \& Anderson, 1986). This argument focuses on existing resources as determinants which lead what types of technology will be used for resolution of problems.

Existing resources not only sets out the problem-solving orientation for new technologies (Cohen \& Levinthal, 1990). By presenting the routines and cognitive framework under conditions of uncertainty, it also promotes a firm's efficient organizational behaviour and active investment in the technology transition (e.g., Becker, 2005; Becker \& Kundse, 2005; Nelson \& Winter, 1982).

On the other hand, existing resources will in some cases limit the selection of a new technology. If firms select a new technology, it may (1) render knowledge and know-how related to existing resources obsolete, (2) change a firm's customer base, and (3) create new technological issues. When a new technology is judged to increase the economic and technological burdens, maintaining the firm's existing technical system is recommended.

The innovation orientation is not determined by a firm's existing resources alone. The behaviour of stakeholders such as customers and related social entities and even the presence of competitors have been noted to exert an influence on the innovation orientation (e.g., Christensen, 1997; Das \& Van de Ven, 2000; Nair \& Ahlstrom, 2003; Tushman \& Rosenkopf, 1992; Smith, 1992; Zhu, Takeishi, \&Yonekura, 2007).

The observation that innovation orientation (technology transition) will be changed as a result of stakeholder trends has been shown by several examples. These include cases where a technology whose adoption might be expected to take time when judged from aspects of technical advantages is selected, improved and commercialized earlier than planned as a result of the presence of social groups and the different interpretations of the technology by these groups (Zhu et al., 2007), and cases where a technology with quite different principles is not driven from the market by a competitor's deliberate technological improvements, but coexists for many years (Nair \& Ahlstrom, 2003).

Without persuading stakeholders especially customers, the idea won't be realized and commercialized, no matter how innovative that idea is. This is the reason that innovation is recognized as influential not only by technological and economic considerations but also by social and political factors (Tushman \& Rosenkopf, 1992).

\subsection{Regulation and Innovation}

Previous research argues that government regulation spur technology innovation (Ashford \& Heaton, 1983; Baumo 1\& Oates 1988; Downing \& White 1986; Jaffe \& Stavins 1995; Marin 1978; Milliman \& Prince 1989; Orr 1976; Porter, 1991; Smith, 1972; Wenders, 1975; Zerbe, 1970). They 
claim that economic incentive, anticipation, stringency and certainty of that regulation drive the development of technology. However, such research merely take notice on how the environmental regulation spurs the technological innovation within each company and does not postulate how some technological innovation has been diffused within the industry. That is partly because most of the researchers use the quantitative data.

Environmental regulation is a social pressure and an obligation to every company. Thus many companies will struggle to develop or buy technological innovation but some specific technology will be adopted. Moreover, without argument about the process of getting competitive advantages, the technological innovation induced by environmental regulation becomes the cost strain to the company which makes them struggle in competitive markets.

Previous research on regulation and innovation lack findings on how environmental regulation affects the technological innovation process and diffusion process. It means they lack the linkage with previous research of innovation process (See Figure 1).

Figure 1: The Lack of Linkage between Previous Studies

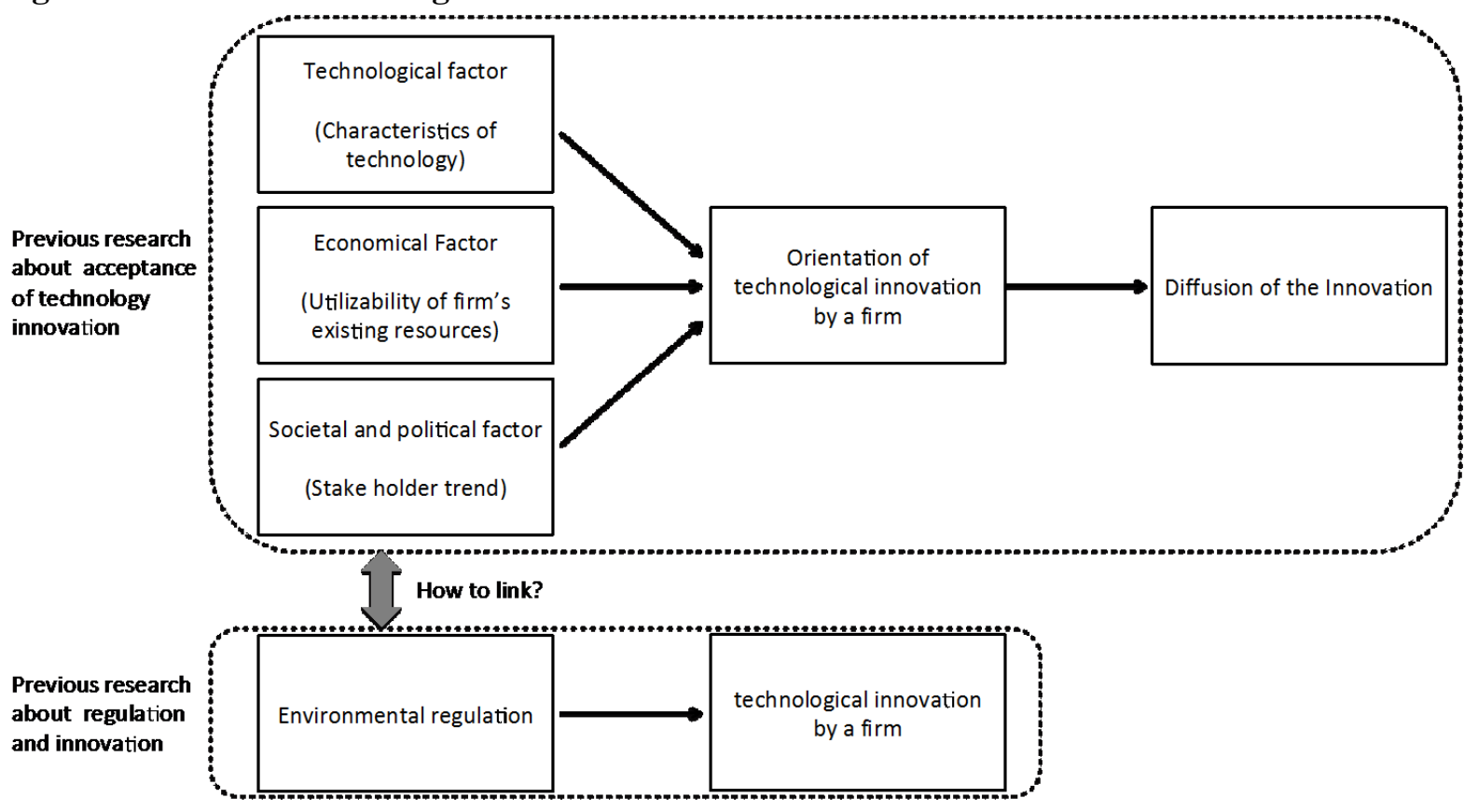

When the environmental regulation is introduced, how can the firm diffuse technological innovation and how can they create competitive advantage? The purpose of this study is to make clear this fact.

\section{Method ${ }^{1}$}

This paper uses the case analysis method to explain how certain technological innovations were developed and spread throughout global markets. The case study discusses the sulphur-free fuel R\&D and commercialization processes by a major Japanese oil company, JX Nippon Oil \& Energy Corporation. The case analysis uses primary data and secondary data. Primary data is seminar data

\footnotetext{
${ }^{1}$ See Koh and Miki (2012) for details.
} 
and interview data ${ }^{2}$. The interviews, which were semi-structured, were conducted with three engineers. The interviews cumulatively lasted for four hours. Secondary data included articles from newspapers, journals, academic papers, and the website of JXNOE.

\section{Case Analysis}

\subsection{Case Summary}

It had become evident that $\mathrm{CO}_{2}$ is a cause of greenhouse gases (GHG). Hence, countries sought to reduce the level of it globally. In Japan, it had become evident the transportation sector accounted for $20 \%$ of $\mathrm{CO}_{2}$ emissions volume. As a result, attention was focused on reducing $\mathrm{CO}_{2}$ emitted by automobiles. The product introduced to address this issue was sulphur-free fuel.

The term "sulphur-free fuel" refers to gasoline and light oil with a sulphur content of 10ppm or less. The first company to develop and spread a method of efficiently distilling sulphur-free gasoline was JXNOE'. The firm completed development of a sulphur-free fuel using its "ROK-Finer" cracked gasoline desulphurization process in 2004, and began sales in the domestic market in January 2005.

The refineries using the "ROK-Finer" cracked gasoline desulphurization process were the Mizushima Refinery, Negishi Refinery and Sendai Refinery; the process was introduced at the first two plants after the start of demonstration trials at the Sendai facility in August 2004. The patented technology for the "ROK-Finer" process has also been licensed to other firms, including the European and the U.S. oil majors. Facilities to produce sulphur-free gasoline using these European and American oil majors' licenses have been installed at 16 refineries in Japan. As a result, the "ROKFiner" process patented technology has a substantive domestic utilization rate of $100 \%$, and gasoline produced as desulphurised catalytically cracked gasoline accounts for $21 \%$ of the total gasoline production volume in Japan. Globally, facilities to produce sulphur-free gasoline using the "ROKFiner" process patented technology are estimated to have been installed at more than 100 refineries as of 2011. This was an epoch-making advance.

The necessity for sulphur-free fuel was recognized not only in Japan, but in Europe and the U.S. as well. There were no firms capable of achieving and diffusing such a product. Additionally, if competitors adopt JXNOE's "ROK-Finer" process patent, there is possibility to have hard time in competition. Hence, it was spread to competitor. How was it possible to spread this process innovation patent throughout the global market? The following section will lead us to one answer to the above question by pursuing the sulphur-free fuel R\&D and commercialization processes at JXNOE.

2 The seminar was organized on Jan.28 ${ }^{\text {th }}$, 2011(15:00 17:00) at Hitotsubashi University Innovation Institute Centre in Tokyo Japan. The Speaker was Shige to Hatanaka, who work for JX Nippon Oil \& Energy central technical research laboratory. The Interview was held on July. $7^{\text {th }}, 2011$, (10:00 12:00) at JX Nippon Oil \& Energy central technical research laboratory.

${ }^{3}$ JX Nippon Oil \& Energy Corporation Ltd. is an entity created in 2010, through the merger of ENEOS and Shinnikou holdings (Japan Energy: JOMO). ENEOS started as a merging company of Mitsubishi Oil Co. Ltd. with Nippon Oil Corporation in 1999. Mitsubishi Oil conducted research on sulphur-free gasoline from 1995, while the search for sulphur-free light oil was pursued at Nippon Oil beginning from 1990. 


\subsection{R\&D and Commercialization Processes}

\subsubsection{Societal Background}

Conventionally, the Japanese domestic standard for sulphur content in gasoline was 100ppm or less. As can be comprehended from the fact that fuel said to be "sulphur-free" is gasoline with sulphur content of $10 \mathrm{ppm}$ or less, such products achieved a significant reduction in sulphur content compared with the conventional standard. Development aimed at producing sulphur-free gasoline had been pursued at domestic oil companies since the early 1990s. However, such activity remained confined to the category of R\&D, and in fact commercialization only progressed after 1997.

That opportunity originated in the Kyoto Protocol adopted in 1997. The text of the Kyoto Protocol stated that advanced nations including Japan will seek to reduce emissions of $\mathrm{CO}_{2}$ and other greenhouse gases (GHG) on a worldwide scale. Specifically, a greenhouse gas emission volume reduction target of 6\% in 2010 compared with the standard year of 1990 was enshrined in the Protocol. Because the volume of $\mathrm{CO}_{2}$ emissions by the transportation sector accounts for over $20 \%$ of Japan's total emissions volume, and exhibits a high rate of increase as well, $\mathrm{CO}_{2}$ reduction measures in the transportation sector were indispensable. Although direct-injection engines and lean-burn engines promising excellent fuel economy attracted attention as a $\mathrm{CO}_{2}$ reduction measure, one fact noted was that because of the sulphur content, fuel efficiency deteriorated when gasoline and light oil with a traditional sulphur content $(30-50 \mathrm{ppm})$ were used. It was speculated that vehicles would have to consume more fuel if fuel efficiency declined, and that this added consumption would make controlling $\mathrm{CO}_{2}$ emissions volume difficult. Consequently society called for stably supplying socalled sulphur-free fuel that would lower sulphur content.

Additionally, fuel sulphur content regulations are legally mandated by each country (See figure 2). In 1999, the EU declared it would convert to sulphur-free fuel in 2009. The U.S. as well decided to set a maximum level of $80 \mathrm{ppm}$ from 2006. In response to this trend in various countries, Japan's Ministry of the environment also decided to establish a sulphur content regulation standard for gasoline. The ministry decided to make gasoline sulphur-free in 2008, one year earlier than in the $\mathrm{EU}^{4}$. As a result, efforts by oil companies in Japan to develop sulphur-free fuel accelerated.

\section{Figure 2: Change in Gasoline Sulphur Content in Japan, Europe and the U.S. and Japan's Efforts}

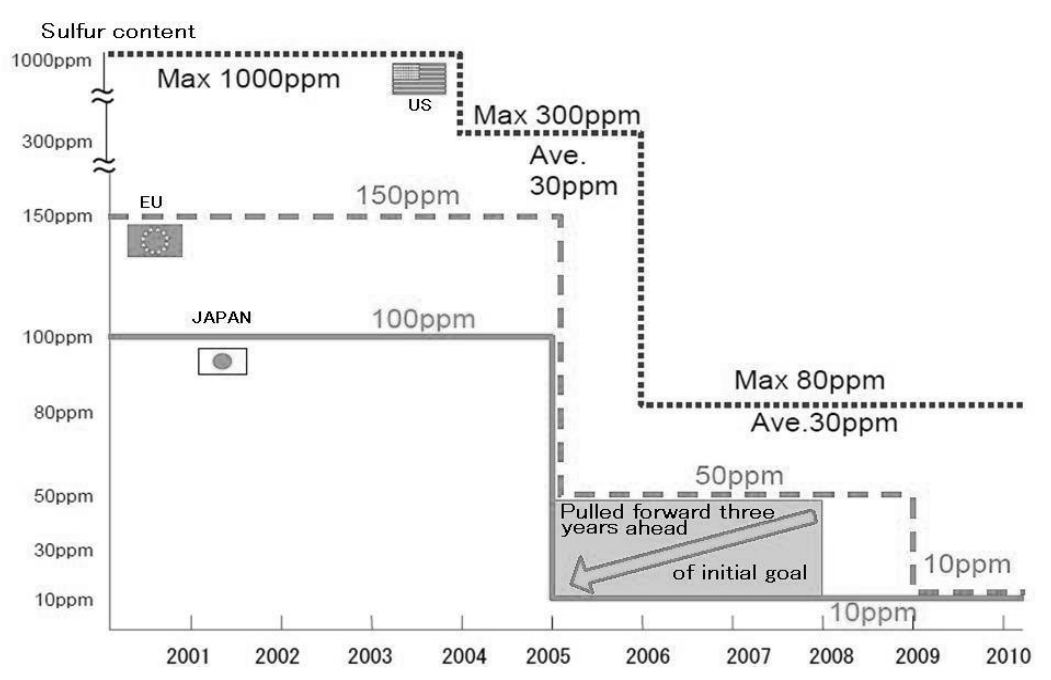

Source: Petroleum Association of Japan(2007)

${ }^{4}$ For light oil, regulations on sulphur content were established in 2007. 


\subsubsection{R\&D Process}

Direct-injection and lean-burn engines as a gasoline engine automotive technology, is generally considered as a measure to meet the greenhouse gases (GHG) provision in the Kyoto Protocol and the reduction of $\mathrm{CO}_{2}$, because they offered excellent fuel efficiency. In addition to that it meets the Ministry of the Environment regulations in particular. However, they presented a number of problems for control of $\mathrm{CO}_{2}$ emissions volume. Because the sulphur content of the gasoline that was used caused fuel efficiency to deteriorate.

First, direct gasoline-injection engines and lean-burn engines increased emissions of nitrogen oxides (NOx), which are hazardous substances, because they draw in large amounts of air through conventional devices, and thus draw in large amounts of nitrogen in the air. NOx has to be eliminated because it decreases the ability of the catalyst to absorb $\mathrm{CO}_{2}$. However, the 30-50ppm of sulphur in conventional gasoline remarkably decreases the removal capacity of the NOx storage and reduction catalyst that reduces NOx.

Second, catalyst poisoning recovery control is necessary in order to eliminate the sulphur constituents of gasoline, but this presents the problem of excessively burning fuel. Consequently it becomes difficult to take advantage of the efficient, low-fuel consumption performance characteristics of direct gasoline-injection engines and lean-burn engines, making control of $\mathrm{CO}_{2}$ emissions more difficult as a result.

In light of these problems, JXNOE decided to undertake the development of sulphur-free fuel that would reduce the sulphur constituent that was hampering the hazardous substance emissions volume control effect. This called for the development of proprietary technology because of the need to sharply reduce the sulphur content compared with conventional gasoline. Given the strong social need, JXNOE independently set an objective of beginning to supply sulphur-free fuel in January 2005, even earlier than required under the central government's regulation.

Removing sulphur using traditional technology presented a problem because it lowered the gasoline octane rating ${ }^{5}$. Gasoline imported by Japan is catalytically cracked gasoline (referred to below simply as "gasoline"), a distillate of petroleum ${ }^{6}$. Heavy oil normally is comprised of a number of carbon chains that form complex molecules if separated using catalysts. For gasoline, its constituents - olefin (40\%), aromatics (20\%) and paraffin (40\%) - are the problem. Because heavy oil contains a large quantity of sulphur to begin with, and this sulphur sometimes enters the cleaved heavy fuel oil molecules, steps are taken to remove the sulphur (desulphurization) by using hydrogen to cause it to react while using a catalyst such as platinum to continuously produce reforming reactions. However, when hydrogen is introduced to cause the desulphurization reaction, olefin, the component with a high octane rating, is hydrogenated and forms paraffin, which has a low octane rating. Gasoline produced by normal distillation has an octane number of 90, and can be mixed with regular gasoline without further processing. However, the octane number of gasoline made to react

${ }^{5}$ The octane rating is the barometer of the difficulty of the self-ignition (it means, pressure or heating make spark up fire). Gasoline is pressured by piston action and it make spark. When it comes close to the upper side of spark plug it makes fire. However, if the spark fire up before it reaches the upper side, piston action pressure bows inversely. As a result, automobile's engine wheeling bucking and it make knocking. High octane rate means self-ignition does not happen under whatever conditions.

${ }^{6}$ Half of the crude oil that is refined is turned into gasoline. 
with hydrogen for desulphurisation will drop to 80 or less, making it unsuitable for use "as is" as gasoline fuel.

Two methods were available for solving this problem. One was a selective hydrogenation desulphurization process to limit the olefin hydrogenation that causes the octane rating to decrease, and the other was a method to restore the lowered octane rating through additional processing. JXNOE poured its effort into the former process. It pursued this alternative because, as the result of research, the desulphurization active site and olefin hydrogenation active site of the catalysts were found to be different, and olefin furthermore was discovered to have two types of hydrogenation active sites. Later, the fact that olefins in gasoline are comprised of about $20 \%$ normal olefins and roughly $80 \%$ iso-olefins was identified as the reason there are two types of olefin hydrogenation active sites. To simultaneously achieve the decrease in the octane rating from the sulphur-free conversion and the hydrodesulfurisation reaction, the normal olefins and iso-olefins were controlled using the different active sites and catalyst preparation technology.

Two types of catalysts were used. One was a catalyst in which cobalt was the principal constituent, and the other was a catalyst whose main component was molybdenum. Both were used simultaneously. Normal olefin was shown to be optimized when the desulphurization rate of the sulphur compound thiophene and the olefin hydrogenation rate are at specific points, depending on the amount of cobalt added. Nevertheless, iso-olefins were not recognized to have a dependency on the cobalt additive amount during hydrogenation, making it possible to take countermeasures such as coking treatment at the active site to cause deposition of coke on the catalyst surface. By controlling the respective active sites of normal olefins and iso-olefins using catalyst preparation technology and applying special processing conditions, JXNOE was able to improve desulphurization activity and control olefin hydrogenation, both of which had been considered difficult in the past. As a result, technology combining improved desulphurization activity with control of olefin hydrogen action, which traditionally had been considered difficult, could finally be achieved.

\subsubsection{The Commercialisation Process}

The process created to analyse the composition of the raw material and optimize reaction conditions using newly developed desulphurization catalysts as a base was the "ROK-Finer" process. This is the process used in equipment for actual commercialization. This process has two characteristics. One characteristic is creating a simulator to accurately predict reactive properties. Specifically, the simulator has two functions. It can predict the catalyst life and the effective desulphurization activity. By using the simulator, application concerning procedures for using the catalysts became possible because the extent to which the catalysts will deteriorate could be forecast.

The other function is controlling the large amount heat generation accompanying the hydrodeisation reaction when predicting the catalyst life and the effective desulphurization activity. As a result, the temperature rise, catalyst longevity and other parameters were clarified by using the JXNOE's catalysts and simulator. The other characteristic is JXNOE's catalysts and simulator "packages." That would enable to make possible operation under the various operating conditions at existing facilities already in service, using different feedstock.

By using JXNOE's "ROK-Finer" process, firms were able to utilize their previous equipment when refining sulphur-free gasoline and improve cost efficiency. In addition, it is believed that by making it possible to predict problems with the simulator, such as life spans of catalysts used in the 
"ROK-Finer" process and the projected percentage increase in heat from their use, JXNOE reduced the risk to customers from accepting the innovation. Gasoline refining equipment utilizing the "ROKFiner" process has been installed and is operating at three JXNOE oil refineries in total: the Sendai Refinery, Negishi Refinery and Mizushima Refinery.

The patented technology for the "ROK-Finer" process has also been licensed to oil majors in Europe, the U.S. and other countries. Domestically, equipment to produce sulphur-free gasoline under the licenses to U.S. and European majors has been installed by Cosmo Oil Co., Ltd. (Ichihara, Yokkaichi, Sakai, Sakaide), Idemitsu Kosan Co., Ltd. (Tomakomai, Ichihara, Chita), JOMO (Kashima, Mizushima) ${ }^{7}$, Showa Shell Sekiyu K.K. (Yokkaichi), Kyushu Oil Co., Ltd. (Oita), Fuji Oil Co., Ltd. (Sodegaura), Seibu Oil Co., Ltd. (Ube), Tonen General Sekiyu K.K. (Wakayama) and Kyokuto Petroleum Industries Ltd. (Chiba). As a result, the domestic share of the patent technology for the "ROK-Finer" process in desulphurised catalytically cracked gasoline is substantively $100 \%$, and accounts for $21 \%$ of Japan's entire gasoline production volume. Worldwide, equipment to produce sulphur-free gasoline using the "ROK-Finer" process patented technology is estimated to have been installed at more than 100 refineries as of 2011. The patent technology for the "ROK-Finer" process is evaluated this highly because it simultaneously conquered the problems of creation of paraffin as a result of the reduction of the sulphur constituent of gasoline and hydrogenation of the gasoline component olefin produced by this process, and the resulting decline in the octane rating, which at that time were considered to be a trade-off. Consequently, the patent technology for the ROK-Finer process is being used for most of the equipment installed around the world at this time.

However, the outcome was diffusion of just the patent technology. The exceptional equipment developed in-house to manufacture gasoline in Japan using the "ROK-Finer" process was not sold in Japan or overseas. Had it been able to sell such equipment, JXNOE might have obtained an even greater business opportunity. However, in Japan the practice of purchasing gasoline manufacturing equipment produced by a rival firm was not an option for each oil company. Moreover, the normal reaction of a firm is to try purchasing such equipment from a manufacturer with experience making such products in the past, rather than from JXNOE, a novice when it came to turning out equipment for producing gasoline. So it may be said that the probability of a domestic competitor buying JXNOE's equipment was almost nil. Moreover, even if by some chance it managed to sell its equipment, it would also have to maintain that equipment in the future. There was no reason to think that JXNOE, which had never manufactured equipment, would be able to maintain it as well. For JXNOE, the decision to keep the manufacture of equipment for producing gasoline using the "ROKFiner" process in-house following its R\&D to produce sulphur-free fuel, and licensing only the patent technology for the "ROK-Finer" process to other companies, can be considered to have been a reasonable judgment.

\section{Conclusion}

Through the case analysis, we show two points. First point is that they innovate the technology of refining sulphur-free gasoline before regulation. They could use full resources for $R \& D$, and they find good technology. Second point is that their technology diffused after regulation. Other firms couldn't take much time for R\&D until the beginning of regulation. That is why most of other firms decided to use JXNOE's patent technology to refine sulphur-free gasoline. From case analysis, we can see that

\footnotetext{
${ }^{7}$ Became JX Nippon Oil \& Energy Corporation in 2010 and changed its brand name to "ENEOS."
} 
technological innovation before regulation have a possibility to give the firm good technological innovation and also give the firm a chance of creating competitive advantage.

There are two implications. First implication is a theoretical one. Previous research about regulation and innovation do not explain how environmental regulation affects the technological innovation process and diffusion process. Through the case study, we described one possibility how can the firm diffuse technological innovation and how can they create competitive advantage when the environmental regulation is introduced. Technological innovation before regulation have a possibility to give the firm high quality finished technological innovation and also give the firm a chance of creating competitive advantage(See Figure 3).

\section{Figure 3: The Process between Environmental Regulation and Competitive Advantage}

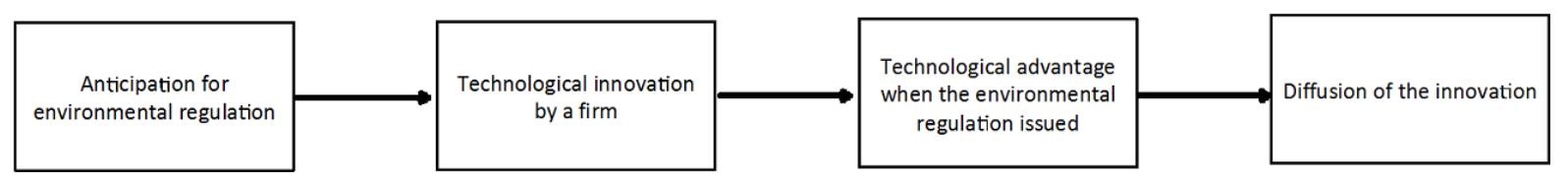

Second implication is for the firms that want to diffuse their technological innovation. Such kind of firms should work on interested party to introduce regulation early. The earlier the introduction of regulation, the more firms focus on their technology. It is easy for the firm to enhance their competitive advantage.

The problem we're facing is lack of research from customer side. We need to study the process how customers utilize new technology innovation. If we can clear up the reason why competing firms decide to utilize "ROK-finer" process patent, we can understand more deeply about the innovation process.

\section{References}

Abernathy, W. J., \& Clark, K. B. (1985). Innovation: Mapping the winds of creative destruction. Research Policy, 14, 3-22.

Ashford, N. A., \& Heaton, G. (1983). Regulation and Technological Innovation in the Chemical Industry. Law and Contemporary Problems, 46(3), 109-157.

Baumol, W. J., \& Oates, W.E. (1988). The Theory of Environmental Policy.(2 ${ }^{\text {nd }}$ ed.). Cambridge: Cambridge University Press.

Becker, M. C. (2005). The Concept of routines: Some clarifications. Cambridge journal of Economics, 29, 249-262.

Becker, M. C., \& Kundse, T. (2005). The Role of routines in reducing pervasive uncertainty. Journal of Business Research, 58, 746-757.

Cohen, W. M., \& Levinthal, D. A. (1990). Absorptive capacity: A new perspective on learning and innovation. Administrative Science Quarterly, 35, 128-152.

Christensen, C. M. (1997).The Innovator's dilemma: When new technologies cause great firms to fail. Harvard Business Press.

Das, S. S., \& Van de Ven, A. H. (2000).Competing with new product technologies: A process model of strategies. Management Science, 46(10), 1300-1316.

Dewar, R. D., \& Dutton, J. E. (1986). The Adoption of radical and incremental innovations: An Empirical analysis. Management Science, 32, 1422-1433.

Downing, P., \& White, L. (1986). Innovation in Pollution Control. Journal of Environmental Economics and Management, 13, 18-29. 
Ettlie, J. E., Bridges, W. P.,\& O’Keefe, R. D. (1984). Organizational strategy and structural differences for radical vs. incremental innovation. Management Science, 30, 684-695.

Forster, R. N. (1986). Innovation: The Attackers advantage. Summit Books.

Henderson, R. M., \& Clark, K. B. (1990). Architectural innovation: The Configuration of existing product technologies and failure of the firms. Administrative Science Quarterly, 35, 9-30.

Jaffe, A.B., \& Stavins, R. N. (1995). Dynamic Incentives of Environmental Regulation: The Effects of Alternative Policy Instruments on Technology Diffusion. Journal of Environmental Economics and Management, 29, 43-63.

Koh, Y., \& Miki, T. (2012). JX Nippon Oil \& Energy Corporation: The development and commercialization process of Sulphur-free fuel. IIR Case Study Case12-05, Institute of Innovation Research, Hitotsubashi University.

Leonard-Barton, D. (1992). Core capabilities and core rigidities: A paradox in management new product development. Strategic Management Journal, 2(3), 11-125.

Liebowitz, S. J., \& Margolis, S. E. (1990).The Fable of the keys. Journal of Law \& Economics, 33(1), $1-25$.

Lundvall, B. A. (1992). National systems of innovation: Towards a theory of innovation and interactive learning. Pinter Pub Ltd.

Marin, A. (1978). The Choice of Efficient Pollution Policies: Technology and Economics in the Control of Dioxide. Journal of Environmental Economics and Management, 5, 44-62.

Milliman, S.R., \& Prince, R. (1989).Firms incentives to promote technological change in pollution control.Journal of Environmental Economics and Management, 16, 52-57.

Nair, A., \&Ahlstrom, D. (2003).Delayed creative destruction and the coexistence of technologies. Journal of Engineering and Technology Management, 20, 345-365.

Nelson, R. R., \&Winter, S. G. (1982). An evolutionary theory of economic change. Bulknap Press/Harvard University Press: Cambridge, MA.

Nonaka, I., \& Nagata, A. (1995). Japanese style innovation system. Hakuto-shobo.

Orr, L. (1976). Exchange versus Grant Transactions in Environmental Models: Incentive for Innovation as the Basis for Effluent Charge Strategy. American Economic Association, 66, 441-447.

Petroleum Association of Japan.(2007). Sulphur-Free Gasoline and the Shift to Diesel Fuel. ( http://www.meti.go.jp/committee/materials/downloadfiles/g71102a05j.pdf )

Porter, M. E.(1991). America's Green Strategy. Scientific American, 264(4), 168

Smith, C. G. (1992). Understanding technological substitution: Generic types, substitution dynamics and influence strategies. Journal of Engineering and Technology Management, 9, 279-302.

Smith, V. K. (1972). The Implications of Common Property Resources for Technical Change. European Economic Review, 3, 469-479.

Takeishi, A., Aoshima, Y., \& Karube, M. (2008). Reasons for innovation: legitimizing resource mobilization for innovation in the case of Okochi Memorial Prize winners. Organizational Science, 42(1), 4-14.

Teece, D. J. (1986).Profiting from technological innovation; Implication for integrations, collaborations, licensing and public policy. Research Policy, 15, 285-305.

Tushman, M. L., \& Rosenkopf, L. (1992). Organizational determinants of technological change: Toward a sociology of technological evolution. In L.L.Cummings and B.M.Staw (Eds.). Research in Organizational Behaviour, 14, 311-347.

Tushman M. L., \& Anderson, P. (1986). Technological discontinuities and organizational environment. Administrative Science Quarterly, 31, 439-465. 
Wenders, J. T. (1975). Methods of Pollution Control and the Rate of Change in Pollution Abatement Technology. Water Resources Research, 11, 393-96.

Zerbe, R. O. (1970). Theoretical Efficiency in Pollution Control. Western Economic Journal, 9(3), 364-76.

Zhu, Y., Takeishi, A., \& Yonekura, S. (2007). The Timing of technological innovation: The case of automobile emission control in the 1970s. Organizational Science, 40(3),78-92. 